\title{
Technical Note: Influence of duration of exposure to field con- ditions on viability of fecal samples for NIRS analysis
}

\author{
ENEAS R. LEITE AND JERRY W. STUTH
}

Authors are Research Scientist, Centro Nacional de Pesquisa de Caprinos (EMBRAPA), Sobral, CE, Brazil 62011 and Professor, Department of Rangeland Ecology and Management, Texas A\&M University, College Station, 77843.

\begin{abstract}
This experiment was conducted to address the issue of spectral integrity of pelleted feces exposed to environmental conditions at different times of the year in near infrared reflectance spectroscopy analysis, using goats as the representative herbivore. Both dietary crude protein and digestible organic matter were predicted. Results indicated that fecal samples collected with up to 7 days of exposure provided similar estimates of diet crude protein and digestible organic matter from samples collected immediately after defecation. Goat feces response to environmental conditions provided useful information as to how collection of many wild herbivores' fecal material could be efficiently sampled for future near infrared reflectance spectroscopy analyses.
\end{abstract}

Key Words: near infrared reflectance spectroscopy, goats, nutrition, crude protein, digestible organic matter

Recent studies have indicated that near infrared reflectance spectroscopy can be a viable tool to predict dietary crude protein concentration and digestibility via fecal profiling for both cattle and goats (Coleman et al. 1989, Leite et al. 1992, Lyons and Stuth 1992, Stuth 1992). Pearce et al. (1993) indicated that spectral integrity of fresh cattle feces can remain useful up to 9 days post-collection when samples were stored in insulated styrofoam containers with freeze packs and allowed to warm up to room temperature.

Goat fecal deposition and physical characteristics show both differences and similarities when compared to other herbivore species. For example, goat defecation patterns across landscapes are much more dispersed than those of cattle. In addition, moisture content in goat feces is much lower than in cattle feces, being $49-54 \%$ and $75-82 \%$ (Putman 1985), respectively. On the other hand, goat feces is similar to the characteristic "pellets" of many wild ruminant herbivores (Putman 1985). Given the success of near infrared reflectance spectroscopy fecal profiling technology, it appears feasible to develop these equations for wildlife species as well (Brooks et al. 1984). However, with the widely dispersed nature of goats and wild herbivore populations, freshly defecated samples may be difficult to

\footnotetext{
This manuscript was published with the approval of the Director, Texas Agricultural Experiment Station, Texas A\&M University as TA-31171.

Manuscript accepted 23 Jan. 1994.
}

obtain in a timely manner.

Therefore, the question emerges as to the spectral stability of fecal pellets from small ruminants when exposed to field conditions for extended periods. The current experiment was conducted to address the issue of near infrared reflectance spectroscopy spectral integrity of pelleted feces exposed to environmental conditions at different times of the year, using goats as the representative herbivore.

\section{Study Area and Treatments}

\section{Field Area}

The study was conducted at the Native Plant and Animal Conservancy area, near Texas A\&M University campus, in College Station ( $30.37 \mathrm{~N}, 96.21 \mathrm{~W})$. The area is representative of the Post Oak (Quercus stellata Wang.) Savannah region of Texas (Gould 1975). Herbaceous vegetation in the study area was dominated by little bluestem (Schizachyrium scoparium var. virile (Shinners) Gould). Other important graminoids present were brownseed paspalum (Paspalum plicatulum Michx.), thin paspalum (Paspalum setaceum Michx.), and broomsedge bluestem (Andropogon virginicus L.). Important forbs occupying the site were Texas croton (Croton texensis (Klotzch) Muell. Arg.), redseed plantago (Plantago rhodosperma Dene.), and oxalis (Oxalis dillenii Jacq.). Yaupon (Ilex vomitoria Soland. in Ait.), post oak and common persimmon (Diospyros virginiana L.) were dominant woody plants in the area.

\section{Field Methods}

The experiment was conducted in 3 trials (February, April, and July, 1992) to study the effect of time of exposure in 3 seasonal conditions (winter, spring, and summer, respectively). Ambient temperature during the trials ranged from 2 to $24^{\circ} \mathrm{C}$ in February, 3 to $29^{\circ} \mathrm{C}$ in April, and 23 to $36^{\circ} \mathrm{C}$ in July. Precipitation events during sampling periods occurred only in February $(6.5 \mathrm{~mm})$ and April $(5.1 \mathrm{~mm})$.

In each trial, 3, free-ranging Spanish goats (Capra hircus) were fitted with fecal collection bags and fresh fecal samples were collected after 4 hours. The same individual goats were used in all trials. These samples were composited and mixed, and 3 fresh subsamples of about $\mathbf{1 0}$ grams were collected for immediate near infrared reflectance spectroscopy processing. The remaining fecal material was placed on the soil surface, simulating normal fecal excretion. To prevent trampling damage and mixing with pellets of free-ranging goats, the pellets were deposited in a grazing exclosure and sampled 
at $12,24,48,72,96,120,144$, and 168 hours after deposition. Three, $10-\mathrm{g}$ subsamples were collected at each sampling period.

\section{Laboratory Procedures}

All fecal samples were dried at $60^{\circ} \mathrm{C}$ in a forced air convection oven for 48 hours and then ground in a Udy mill to pass a $1-\mathrm{mm}$ screen. Samples were again placed in the oven for 12 hours to stabilize moisture before scanning (Lyons and Stuth 1992). After removal from the oven, samples were placed in a desiccator for 1 hour to cool to ambient temperature (Lyons and Stuth 1992). Samples were then packed in sample cups with quartz windows, and scanned with a Pacific Scientific near infrared reflectance Scanner 4250 and the spectra generated were stored in a micro-computer linked to the scanner equipment (Williams and Norris 1987). Dietary crude protein (\%) and digestible organic matter (\%) were determined using fecal near infrared reflectance spectroscopy equations described in a previous study (Leite et al. 1992).

The calibration equation used in this study for crude protein analyses consisted of 163 samples. Five wavelengths resulted in an $R^{2}$ of 0.94 with a standard error of 1.12 . The validation analysis for crude protein resulted in an $R^{2}$ of 0.94 with a standard error of 1.28 , a slope of 1.18 and a bias of 0.16 . The laboratory standard error for crude protein was 0.91 . The calibration equation for digestible organic matter analyses consisted of 86 samples. Four wavelengths resulted in an $R^{2}$ of 0.93 with a standard error of 2.02 . The validation analysis for digestible organic matter resulted in an $R^{2}$ of 0.92 with a standard error of 2.12 , a slope of 0.91 and a bias of 0.18 . The laboratory standard error for digestible organic matter was 1.98 .

\section{Statistical Analyses}

The possible seasonal influence on sample stabilization was studied with the analysis of each individual trial through a completely random design method (Freund and Littell 1981, Lentener and Bishop 1986). The periods (hours) of collection after defecation were assigned as treatments. Tukey's Studentized Range Test at 95\% level of probability was used to separate differences among treatments (Freund and Littell 1981).

\section{Results and Discussion}

Mean near infrared reflectance spectroscopy analyses of crude protein and digestible organic matter content of predicted diets from feces collected throughout 168 hours ( 7 days) post defecation were not affected $(P>0.05)$ by duration of exposure, regardless of season (Figs. 1 and 2). Standard errors were $0.218,0.232$ and 0.215 for crude protein and $0.354,0.511$ and 0.576 for digestible organic matter, for winter, spring, and summer trials, respectively. Consequently, the slight fluctuations in crude protein and digestible organic matter contents within each season studied could be attributed to random variations in samples collected.

In a study conducted to detect chemical and physical changes over time in fecal pats on the ground, Hinnant and Kothmann (1988) reported that cattle feces collected after 48 and 72 hours of exposure were decimated by insect activity during the summer trial. Researchers in Oklahoma indicated that concentrations of fecal nitrogen, neutral detergent fiber, and acid detergent fiber in deer pellets collected during the fall, remained constant until 24 days after defe-

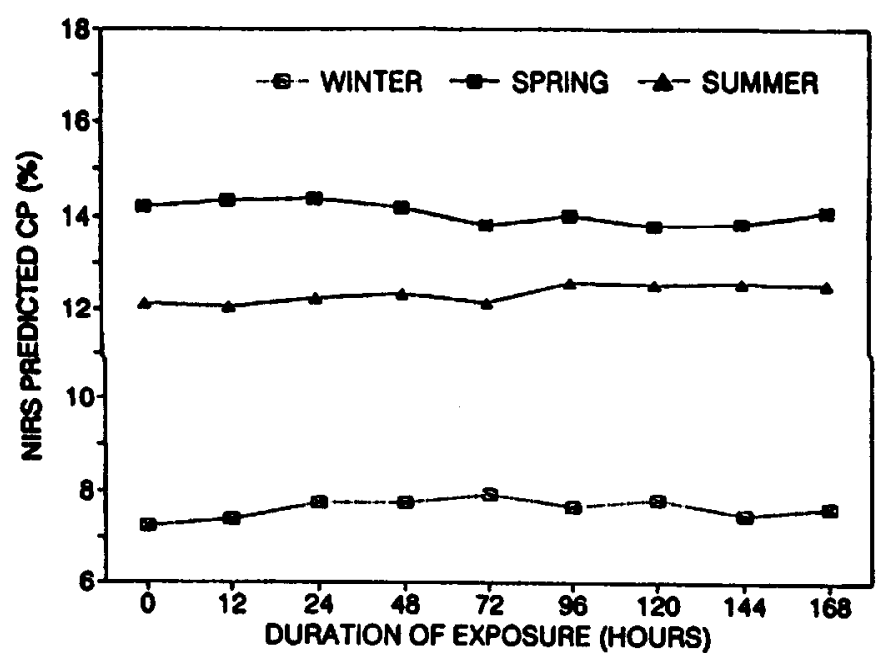

Fig. 1. NIRS predicted crude protein (CP) from fecal material subjected to varying durations of exposure in winter, spring, and summer 1992, in College Station Texas. Means within a season did not differ $(P>0.05)$ among the 9 exposure durations.

cation (Jenks et al. 1990). In the present study, fecal sample usefulness for near infrared reflectance spectroscopy analysis did not appear to be affected by the biotic and abiotic factors occurring during the observed trials. In contrast to cattle feces, goat pellets have a low moisture content (Putman 1985), and their fast drying characteristics may be a factor to act against damage caused by insects. Therefore, the small fluctuations in crude protein and digestible organic matter contents throughout the sampling periods may be attributed to the random effects associated with the process of collection, a possible slight variation in botanical composition of the subsamples within each trial, and inherent variations of the near infrared reflectance spectroscopy equation.

Although precipitation can be an important factor affecting degradation rate of fecal pellets (Harestad and Bunnell 1987), this experiment was not designed to examine the effect of precipitation on fecal nutrients concentrations. It was assumed that samples exposed to pre-

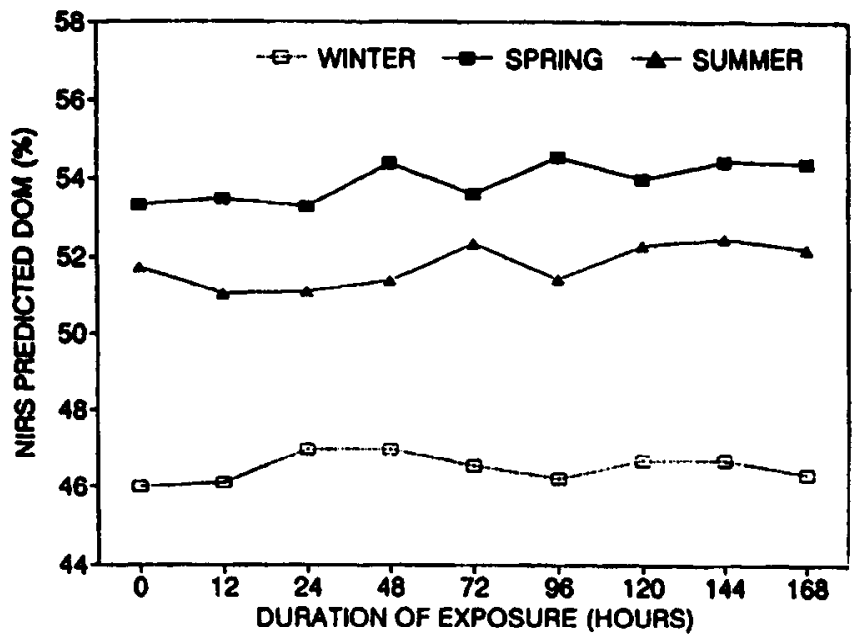

Fig. 2.NIRS predicted digestible organic matter (DOM) from fecal material subjected to varying durations of exposure in winter, spring and summer, 1992, in College Station, Texas. Means within a season did not differ $(P>0.05)$ among the nine exposure durations. 
cipitation were unsuitable for near infrared reflectance spectroscopy analysis. Thus, to evaluate time of exposure on pellet groups, the samples were covered during the precipitation events. However, feces exposed to ambient conditions in the field, experienced extreme fluctuations in temperature, sunlight, humidity, and wind within season. Results of the present study indicate that pellet samples from goats exposed to environmental conditions, for periods no longer than 7 days, can be used to predict dietary crude protein and digestible organic matter with similar levels of precision to fecal samples collected at the time of defecation.

\section{Conclusions}

Age of goat fecal pellets should not constrain remote sampling strategies for fecal near infrared reflectance spectroscopy monitoring within the sampling period ( $<8$ days) reported in this research. However, it is recommended that samples be collected as soon as possible after defecation, to avoid possible effects of precipitation, trampling, insect loss or addition, crusting, and the risks of collecting samples with longer periods of exposure than those suitable for near infrared reflectance spectroscopy and chemical analysis.

\section{Literature Cited}

Brooks, J., M. Anderson, and P.J. Urness. 1984. Infrared reflectance analysis of forage quality for elk. J. Wildl. Manage. 48:254-258.
Coleman, S.W., J.W. Stuth, and J.W. Holloway. 1989. Monitoring the nutrition of grazing cattle with near infrared analysisof feces. p. 881-882. In: Proc. XVI Int. Grassl. Congr., Nice, France.

Freund, R.J., and M. Littell. 1981. Guide to SAS linear models. SAS Inst. Inc., Cary, NC 27511.

Gould, F.W. 1975. Texas plants: a checklist and ecological summary. Texas Agr. Exp. Sta. MP-585.

Harestad, A.S., and F.L. Bunnell. 1987. Persistence of black-tailed deer fecal pellets in coastal habitats. J. Wildl. Manage. 51:333-37.

Hinnant, R.T., and M.M. Kothmann. 1988. Collecting, drying, and preserving feces for chemical and microhistological analysis. J. Range Manage. 41:168-171.

Jenks, J.A., R.B. Soper, R.L. Lochmiller, and D.M. Leslie, Jr. 1990. Effect of exposure on nitrogen and fiber characteristics of white-tailed deer feces. J. Wildl. Manage. 54:389-391.

Leite, E.R., J.W. Stuth, R.K. Lyons, and J.P. Angerer. 1992. Using near infrared spectroscopy to monitor nutritional status of free-ranging goats. p. 36-42. In: 1992 Sheep \& Goat, Wool \& Mohair CPR. PR-4934.

Lentener, M., and T. Bishop. 1986. Experimental design and analysis. Valley Book Co., Blacksburg, Virg.

Lyons, R.K., and J.W. Stuth. 1992. Fecal NIRS equations for predicting diet quality of free-ranging cattle. J. Range Manage. 45:238-244.

Pearce, R.A., R.K. Lyons, and J.W. Stuth. 1993. Influence of handling methods on fecal NIRS evaluation. J. Range Manage. 46:274-276.

Putman, R.J. 1985. Facts from faeces. Mammal. Rev. 14:79-97.

Stuth, J.W. 1992. The effects of brush characteristics and stocking rate on meat goat nutrition and production. p. 123-140. In: Proc. Intern. Conf. on Meat Goat Prod., Manage. and Market., Laredo, Tex.

Williams, P.C. and K. Norris (eds.) 1987. Near-Infrared Technology in the Agricultural and Food Industries. American Association of Cereal Chemists, Inc., St. Paul, Minn. 330 pages.

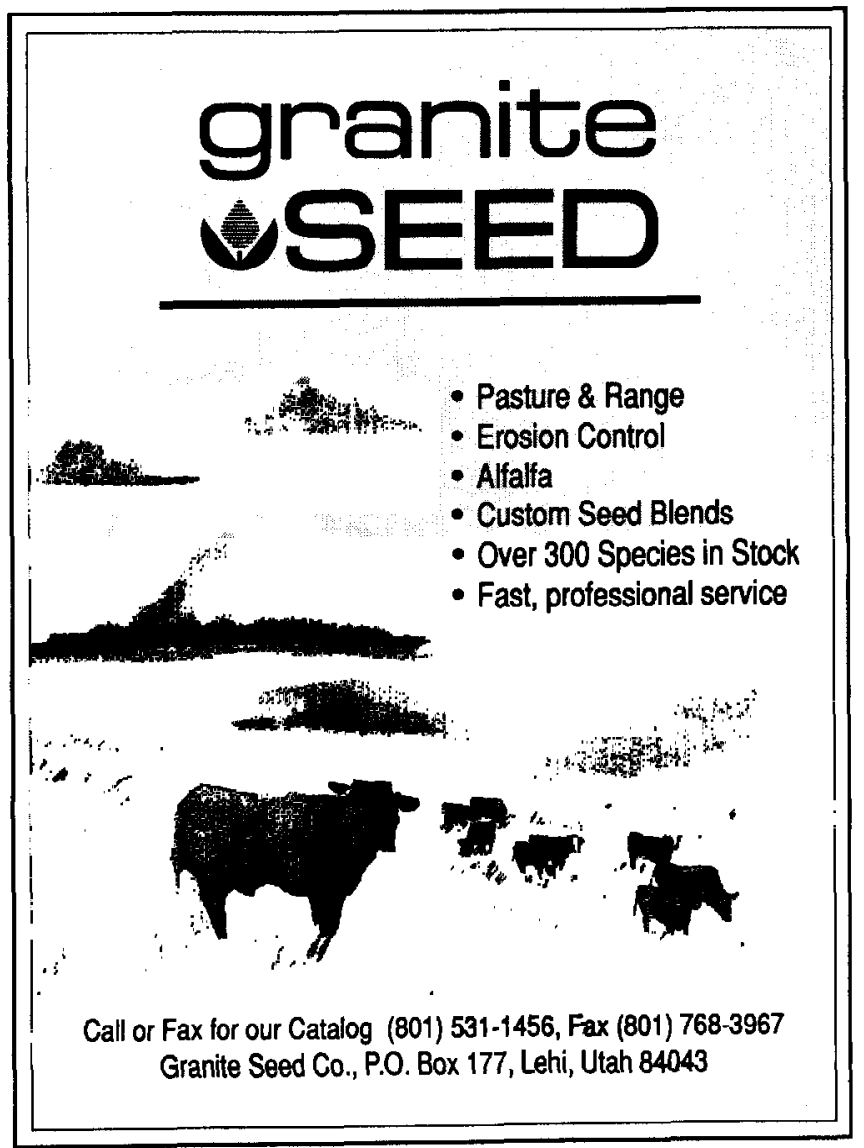

